\title{
Gdansk Bay sea bed sounding and classification of its results
}

\author{
Grażyna Grelowska1), Prof. \\ Eugeniusz Kozaczka ${ }^{1,2)}$, Prof. \\ Sławomir Kozaczka'1), M.Sc. \\ Wojciech Szymczak1), M.Sc. \\ 1) Polish Naval Academy, Poland \\ 2) Gdansk University of Technology, Poland
}

\begin{abstract}
The main goal of this paper is to describe the results of sounding the Gdansk Bay sea bed by using a SES2000 Standard parametric sub-bottom profiler. Quality of data obtained during trials depends inter alia on a proper location of transducer array to reduce influence of pitch, roll and heave motions as well as ship self noise (resulting from bubbles due to propeller and flow around hull, vibration generated by main engine and auxiliary devices). Furthermore, calibration of complementary units such as GPS, heading sensor, MRU-Z motion sensor and navigation devices make sea-bed investigating system capable of working with its whole capability. Results of so prepared surveys have been presented and discussed. They contain also an elaborated map of Gdansk Bay with preliminarily classified sea-bed materials and description of most interesting areas.
\end{abstract}

Key words: sea bed sounding; parametric sub-bottom profiler; sea bed structure

\section{INTRODUCTION}

Examination of the upper layer of sea bed can be performed with the use of invasive methods as well as non-invasive ones. The invasive methods apply only to the local structure of the sea bed, and are associated with geographical coordinates of the bore-hole point (point of evaluation). In addition, in such case a subtle structure of actual image of the bottom is destroyed. The non-invasive methods are mainly seismic ones which are rather suitable for determining the geological structure of the sea bed in relation to large depth $[14,16]$. However, for the bottom layer they are relatively inaccurate. An alternative solution is to use acoustic methods which make accurate determining the sea-bed stratification, possible. These methods are non-invasive and relatively versatile. However there is a problem of penetration of bottom sediment by acoustic waves $[1,2,9]$. Attenuation of elastic waves by bottom sediments is about 1000 times larger than by the water [13]. For this reason the high-frequency waves are mostly reflected upon the water - bottom border surface.

With taking into account the relevant constraints a parametric source of acoustic waves can be applied in such case. The principle of operation of such source is that, as a result of the nonlinear interaction between two large-intensity acoustic beams in the area of common impact of the beams, a new wave is formed in the area of a volumetric character [12]. As the beams called primary, differ only slightly in frequency, we get a wave called the differential wave whose frequency is equal to the difference in frequency of the primary waves. Such wave maintain the features of primary waves and therefore is of a high directivity. Due to the area of its generation which is three-dimensional, it has no additionally adverse side lobe. The properties were used in the construction of the parametric sonar, inter alia in the SES 2000 Standard parametric echosounder [17]. Extensive research of sea bottom in Gdansk Bay waters was performed with the use of this echo sounders $[3-8,10,11]$.

\section{RESEARCH VESSEL}

The platform for sea trials was set on board s/y Windspeel, a small research vessel. The main device was the SES-2000 Standard sub-bottom echo sounder which consisted of the main unit situated below the deck and the transducer array mounted on aluminium arm starboard. The unit makes it possible to radiate low frequency sounding pulses set by the user within the range from 4 to $15 \mathrm{kHz}$ and a definite changeable length. An interesting function during sounding was the option of obtaining sub-bottom data by applying two or three different pulses with user - defined frequencies. During the sea trials in question the frequencies of $4 \mathrm{kHz}, 8 \mathrm{kHz}$ and $12 \mathrm{kHz}$ were set and combined to each other. As the best weather conditions are during calm sea which is not always achievable, hence a beam steering to compensate for vessel pitching and rolling was necessary.

The obtained data were stored on hard disc in the two formats: *.SES one which includes information about signal 

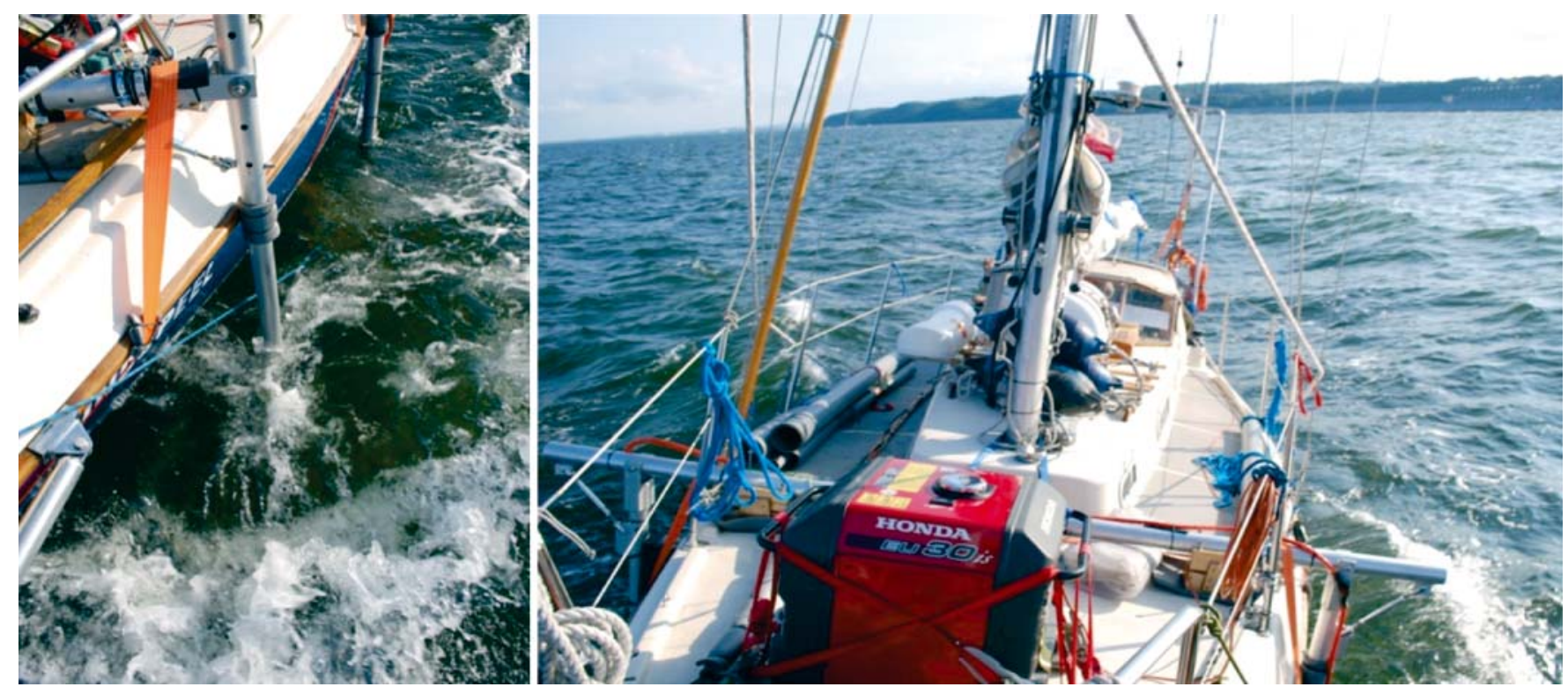

Fig. 1. Research vessel with installed equipment

envelope and *.RAW data containing full waveform. The whole unit was fed with $230 \mathrm{~V}$ (AC) provided from DC-AC converter connected to the set of three 110 Ah gel batteries charged during trials from solar batteries and a generator driven by vessel's engine. During breaks in measurements the charging was provided by on-board $230 \mathrm{~V}$ Honda electric generating set. Additionally sea bed was sounded with the use of the multi-beam EM3002 echo sounder whose transmitted pulses were synchronized by means of an external trigger installed in the SES-2000 sounder that ensured undisturbed results. Complementary devices like the MRU-Z sensor of pitch, roll and heave motions precise GPS with heading sensor were installed and calibrated on the vessel. Signals from the sensors were distributed to the devicesby means of RS-232 splitters During the trials sound velocity profiles were stored in SD204 unit and put in to controlling programs of sub-bottom and multi-beam echo sounder. The investigated area and transects selection along which the sounding took place were determined on the basis of geological maps delivered by Państwowy Instytut Geologiczny (State Geological Institute) [15]. The appropriate data were delivered to the navigation software (Nobeltec) connected to autopilot, that ensured a satisfying accuracy of sounding along the set tracks. To help the skipper to control situation on sea two monitors were duplicated in cockpit to display navigation map and sounding results. The research vessel during measurement trials on Gdansk Bay is presented in Fig. 1.

The devices necessary to ensure proper work of the whole unit were placed on specially prepared working racks inside the vessel (Fig. 2). Before beginning the trails on sea the units were calibrated in harbour and checked during work with different parameters and configurations. Additionally, the electric system was tested and checked against possible emission of noise which could influence sounding equipment.

Special RS232 splitters were implemented into the system to avoid duplication of the units delivering information such as position and motion data.

\section{OBTAINING SEDIMENT SAMPLES}

During all sea trials a diver prepared for such action was collecting samples of material taken from bottom's surface and other layers according to a type of sediment. The samples were

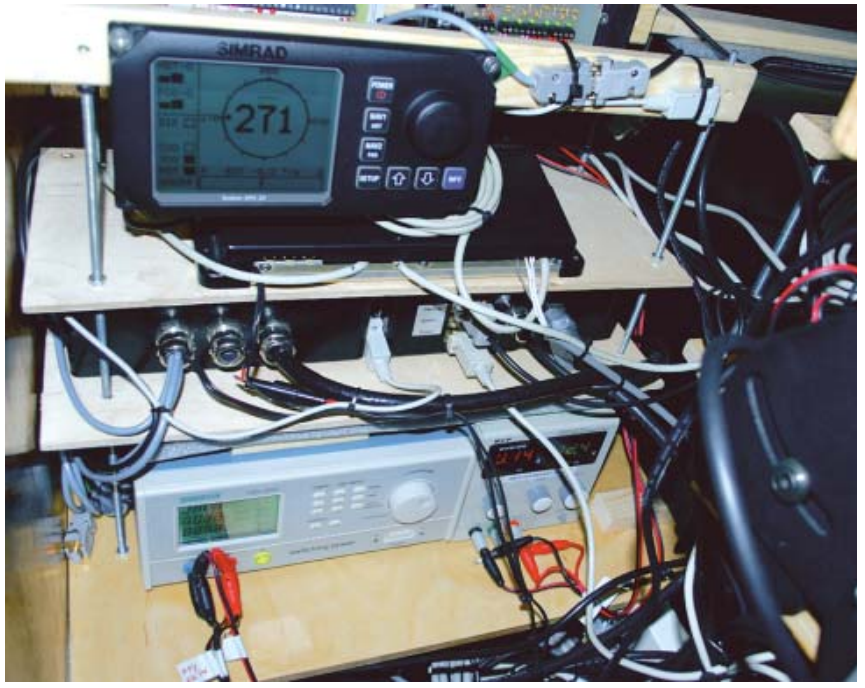

Fig. 2. Complementary devices

stored in special containers, and then examined and classified. Additionally, it was necessary to collect enough amount of materials to be used during trials in $30 \mathrm{~m}$ long water tank of Gdansk University of Technology, where influence of different kind of materials on the parametric echo sounder records was measured and then used to prepare database for comparison of results from sea trials with data obtained during the "artificial sounding".

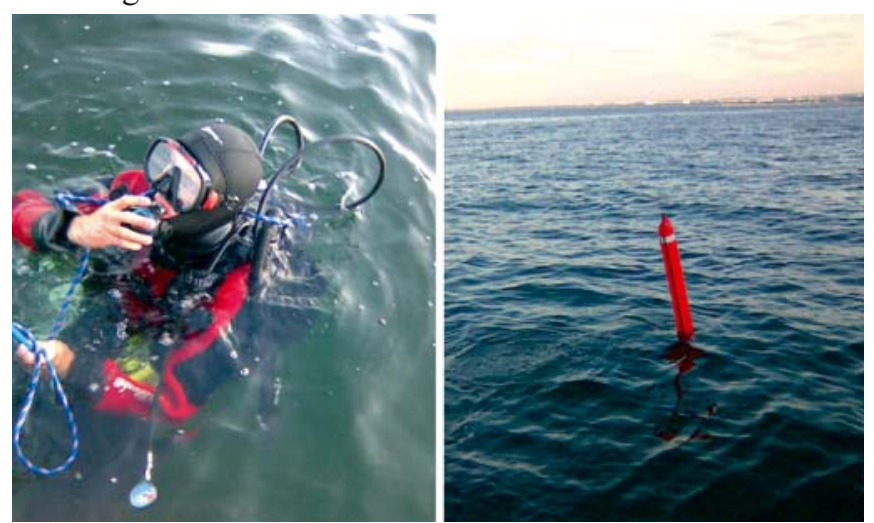

Fig. 3. Diver who prepares for taking bottom sediment samples 


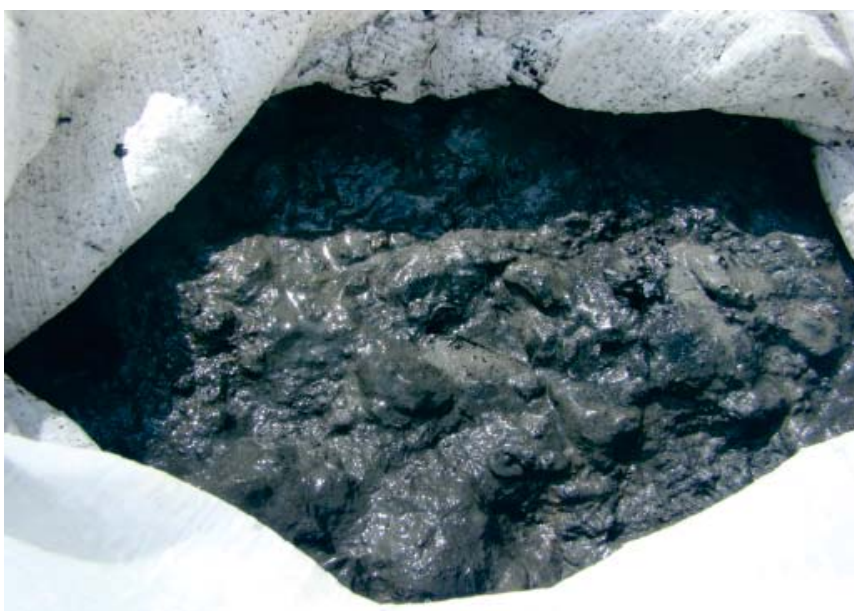

Fig. 4. Mud dug out of sea bottom

An example container filled with mud taken from sea bottom is presented below. Collecting such sediment was most difficult for the diver because of no visibility due to cloud of silt produced during digging the material.

Enlarged pictures of sediments are presented in Fig. 5 and 6 . The example clearly shows difference in bottom layer structure. The example IV illustrates the sample of sand which results in high power echo compared with the sample of mud of a low penetration - example III.

Owing to the data which uncover clear parts of the cliff it was possible to elaborate pictures of the structure of such sediment layers by collecting the sediments and comparing them with the samples taken from sea bottom. Real image of such structure provides more information on its geological nature. In Fig. 7 is presented an example of enlarged pictures of materials taken from the pointed parts of the cliff material layers.
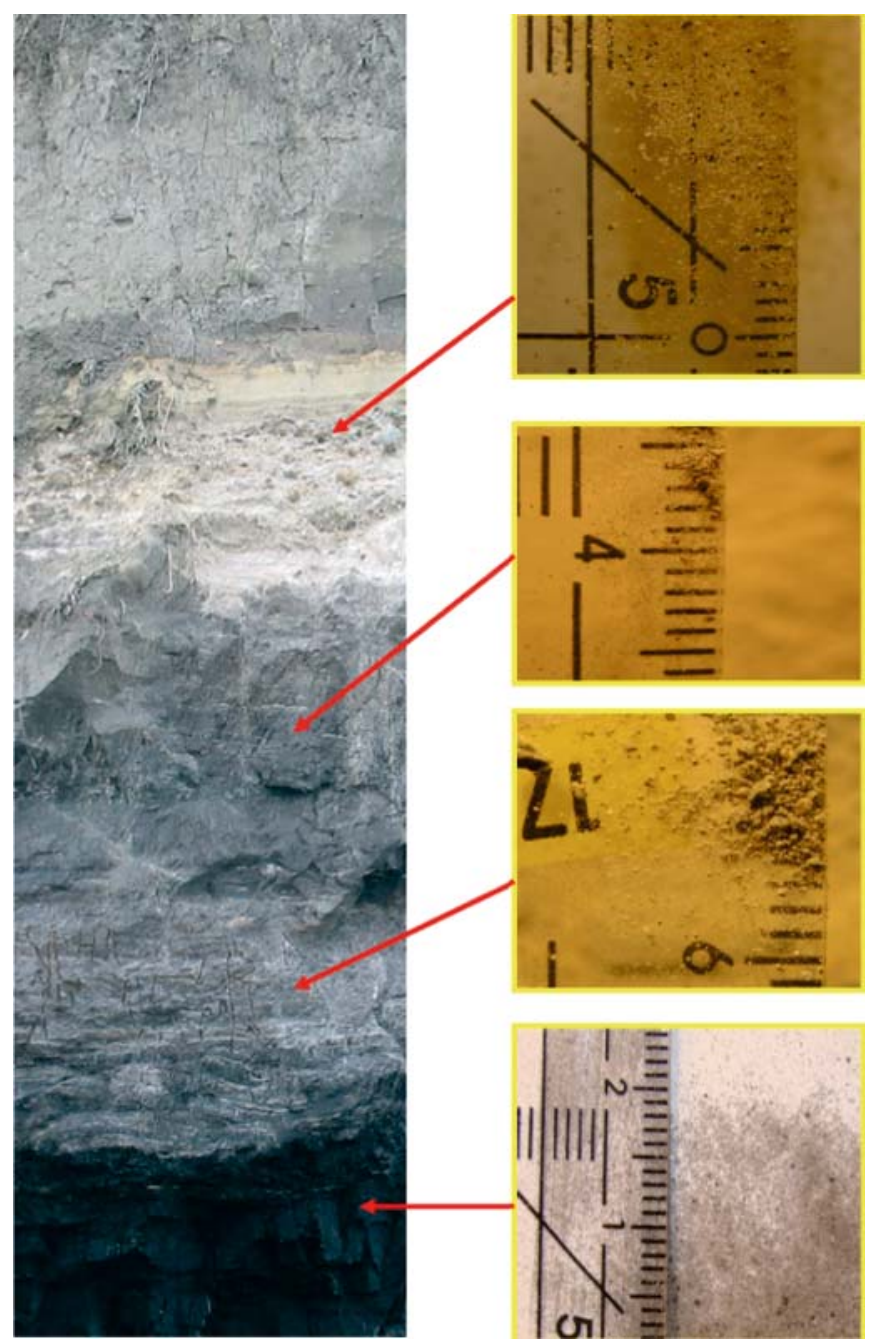

Fig. 7. Cliff material layered structure

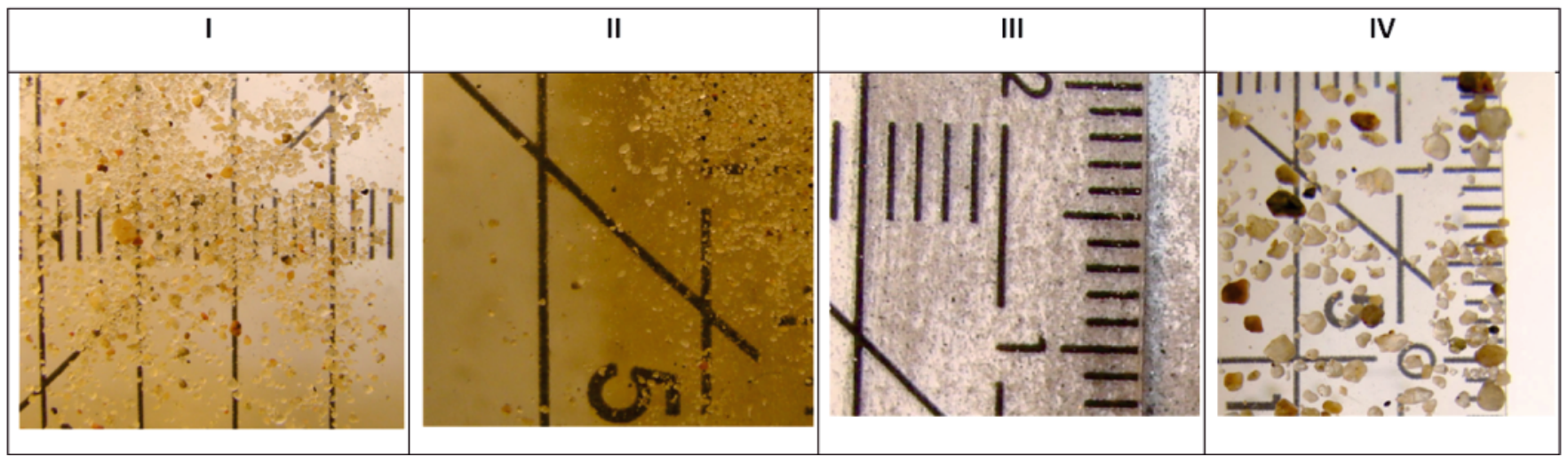

Fig. 5. Sediment samples in macro view, part 1

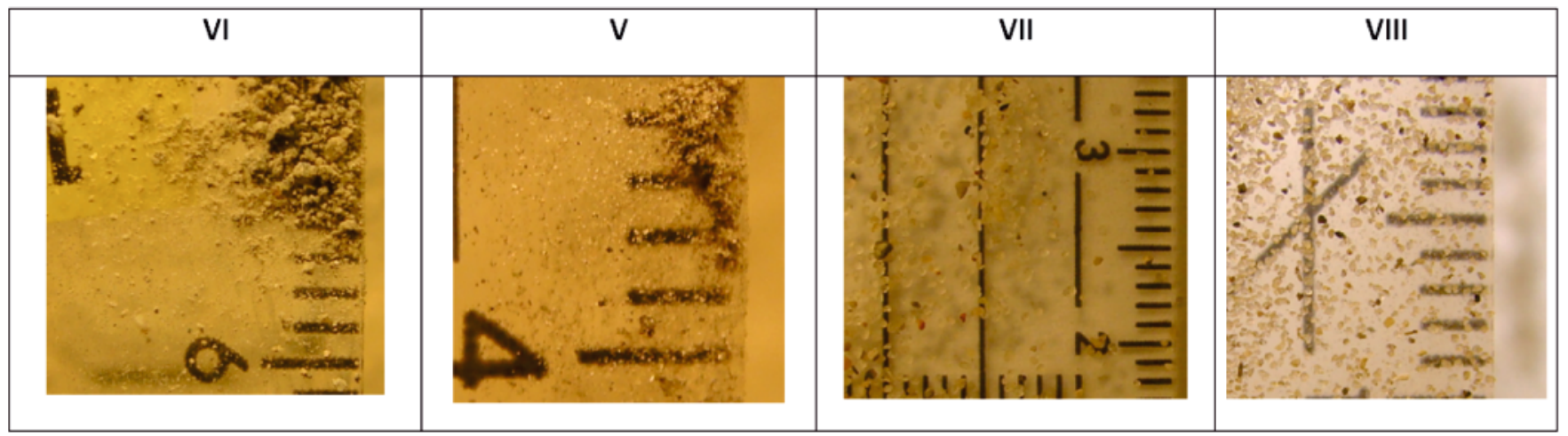

Fig. 6. Sediment samples in macro view, part 2 


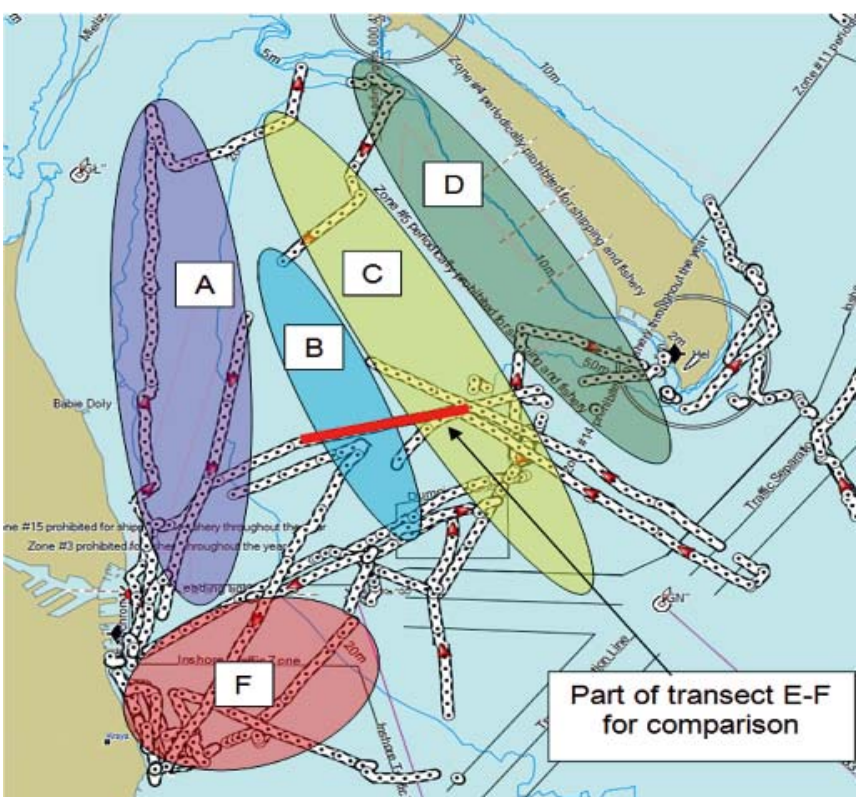

Fig. 8. Map of Gdansk Bay which shows classification of the bottom penetration areas. $\boldsymbol{A}$ - the area called "hilly sub-bottom"; $\boldsymbol{B}$ - the area of medium sounding depth (up to 5 m penetration); $\boldsymbol{C}$ - the area of the deepest penetration (up to $30 \mathrm{~m}$ ); $\boldsymbol{D}$ - the area of a highly reflective bottom (no penetration); $\boldsymbol{E}$ - the area of a mixed type of penetration (from $1 \mathrm{~m}$ up to $10 \mathrm{~m})$; Thick red line - a part of the transect $\boldsymbol{E}-\boldsymbol{F}$ - taken for comparison

\section{EXAMPLES OF SEDIMENT CLASSIFICATION}

After several trails in Gdansk Bay it was possible to elaborate a basic classification of sub-bottom penetration areas indicated on the map (Fig. 8) which shows five main types of the results.

Sample echograms corresponding to the marked areas are presented below: the first (Fig. 9) called "hilly sub-bottom", shows a typical bottom which reflects strong echo, and another bottom profile at first glance looking like "hills", where the top of it sometimes touches the bottom and even penetrates it e. g. in the point I. After examination, sediments of sand silt and clayey silts were found, what confirmed information taken from the geological map. From the point of view of the layered structure the area $\mathrm{E}$ is rather less interesting as it combines places with penetration up to $10 \mathrm{~m}$ with those of strong echo only and of no information of extra layers which corresponds to sediments like sand from which whole sounding pulse is reflected. The looking and analyzing of such long echograms gives possibility to determine permanence of sub-bottom layer.

The other results were also compared with the data delivered by Państwowy Instytut Geologiczny, representing a geological map of bottom structure (Fig. 11), prepared by using different methods including taking deep sediment samples. When analyzing echogram results shown in Fig. 12 one can notice that a part of sounding which dealt with sand characterized shallow penetration, and in the places where silt and clay

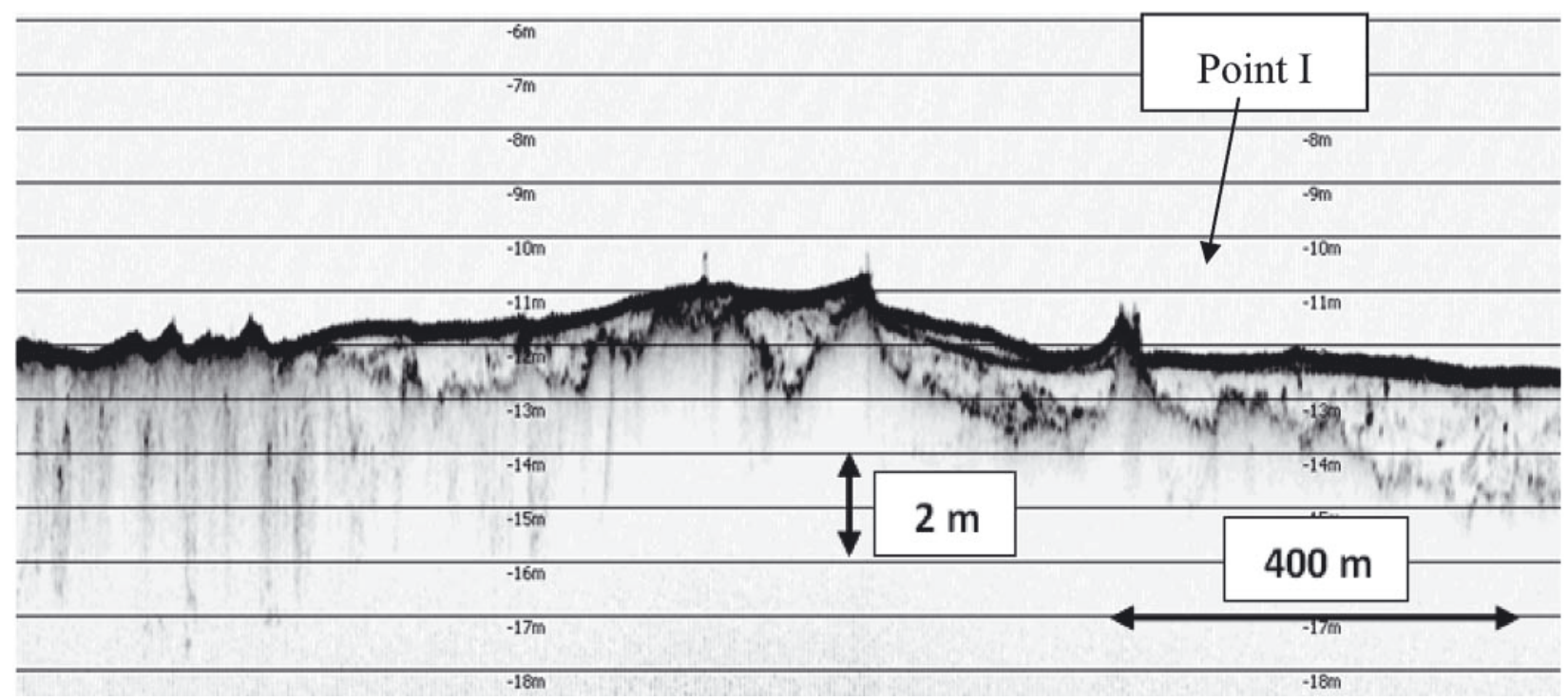

Fig. 9. Hilly sub-bottom profile - area A

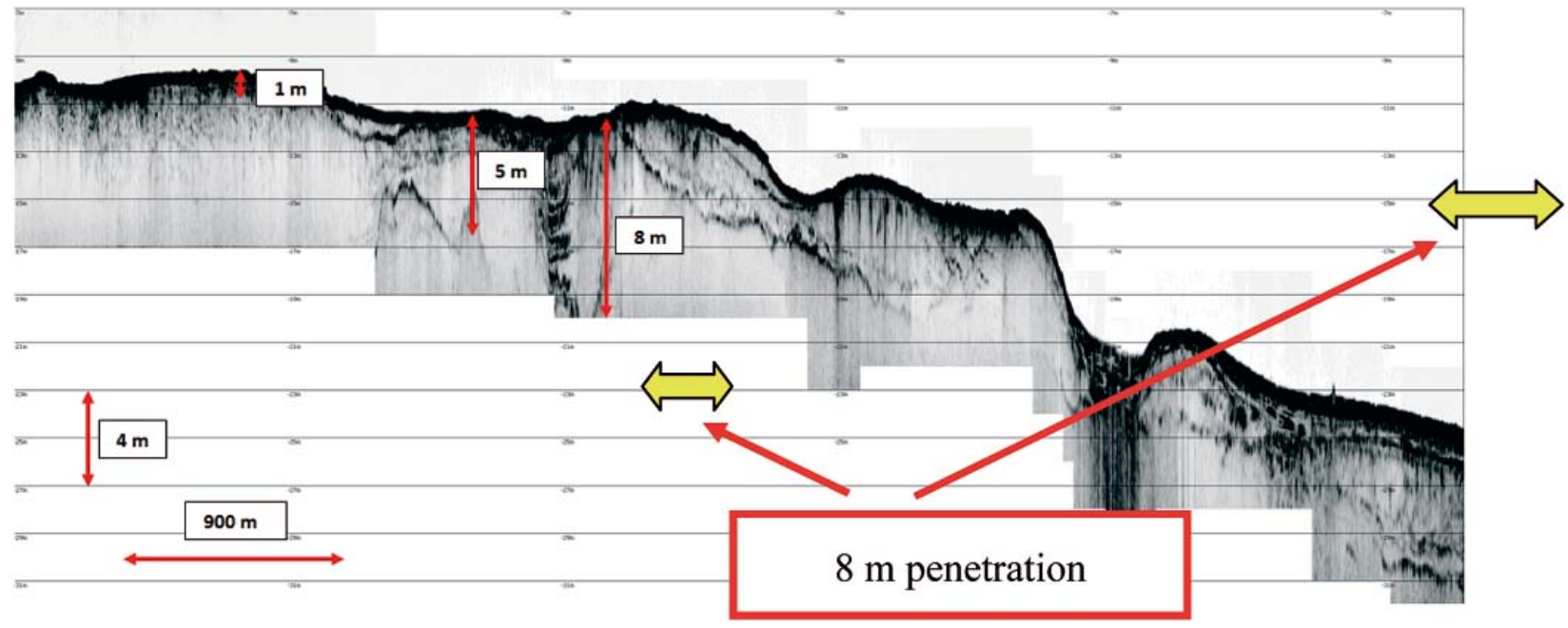

Fig. 10. The area of a mixed type of penetration depth (from $2 \mathrm{~m}$ up to $10 \mathrm{~m}$ ) - area $\mathrm{E}$ 


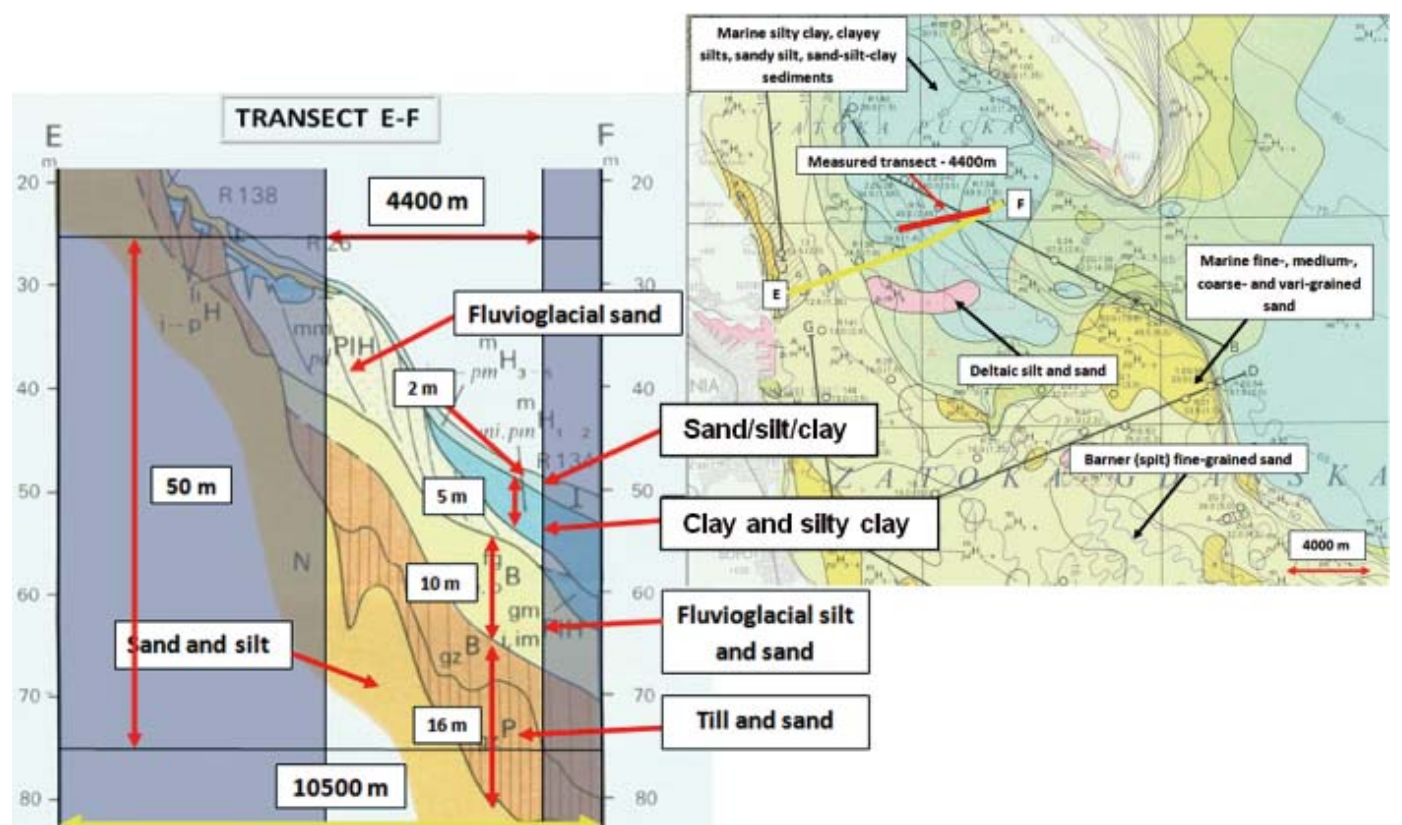

Fig. 11. Geological structure of the marked transect

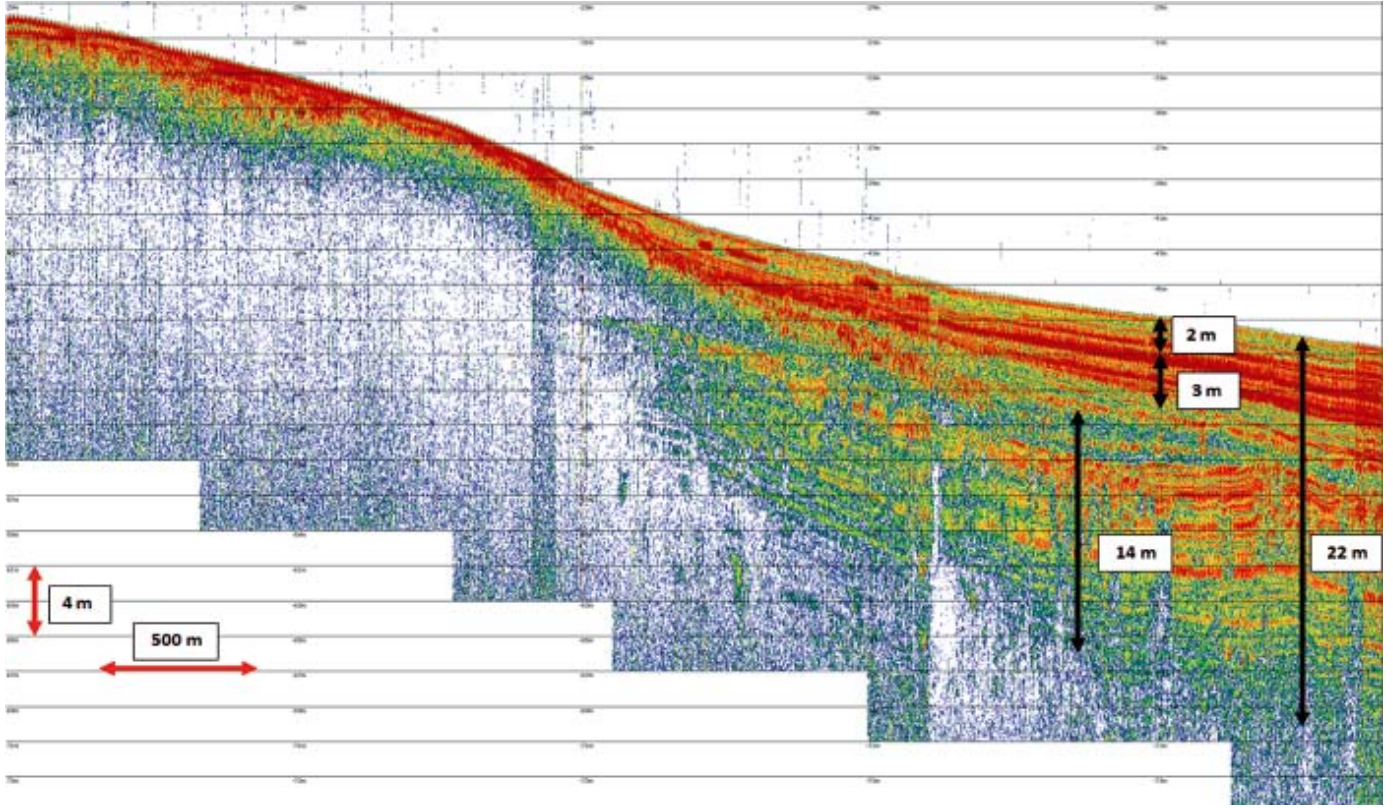

Fig. 12. Echogram taken along the transect marked with red line in Fig. 11

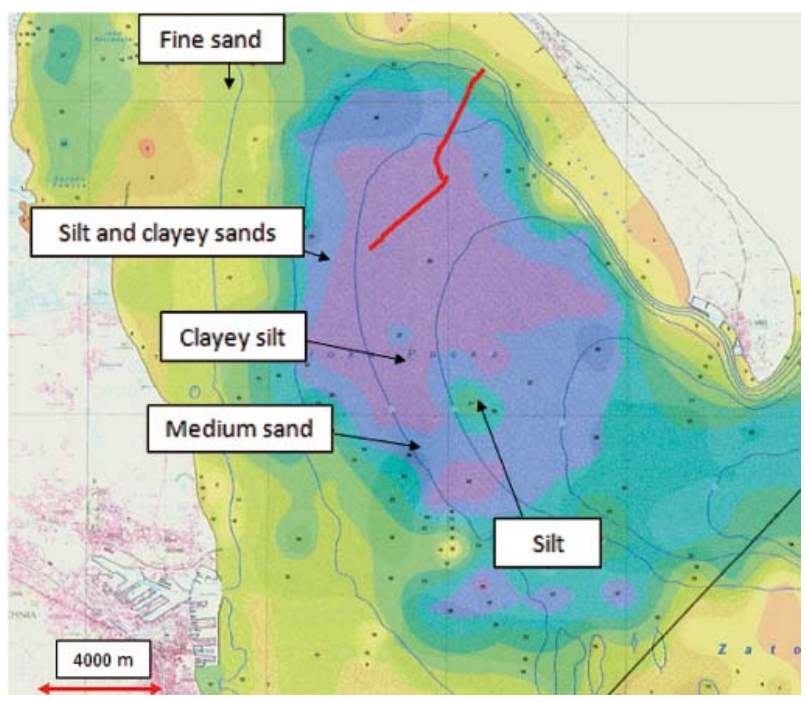

Fig. 13. Geological map with the marked transect occurred deeper souding results were obtained. Comparison of the results was possible due to the use of devices to precisely contol of the research vessel motion and sail along selected transects. During the measurements the parametric echosounder was tested with different sounding pulse frequencies to acquire information about echosounder parameters during sounding the deep bottom penetration areas.

The last results come from the mixed areas B, C and D. They were taken along the transect marked with red line depicted on the geological map.

When analyzing of the results (Fig. 14) is started from the left side, the data obtained in the area B representing strong echo reflected from hard bottom are there visualized. When passing to B sector a deeper penetration can be noticed - not as deep as in the middle of this area but with the same characteristic structure. The end of the echoogram shows rapid change of penetration depth compared with bathymetric data and change of colour of the surface from orange to red which is related to a higher level of the bottom echo strength. 


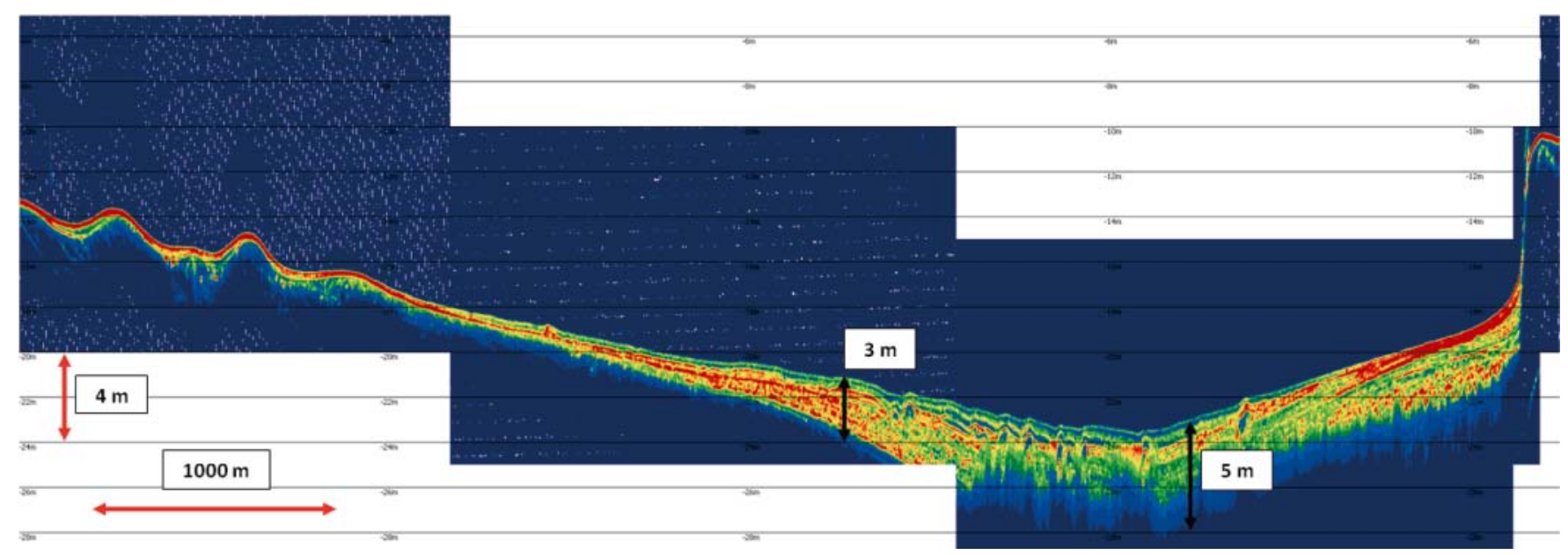

Fig. 14. Echogram taken along the transect marked on the geological map (Fig. 13)

\section{SUMMARY}

In the paper is presented an experimental acoustic method for determination of sea bed material as well as structure of the upper layer of the sea bottom.

After performance of trials and data processing, their results were analyzed and compared with those obtained during the trials in the water tankthat was satisfactorily implemented into the first step of classification of sediment layers.

Additionally experiments in preparing long echograms (over a few kilometers) clearly showing changes in sediment structure, have ended with good results that was confirmed by the promising spectrograms presented in this paper.

The systematic approach to the problem, consisted in starting with measurements of some acoustic parameters of sediments in laboratory conditions and then passing to the in situ investigations, resulted in determination of different properties of sea bottom in some areas of Gdansk Bay.

\section{Acknowledgments}

The investigations was partially supported by the Ministry of Science and Higher Education in the frame of the fund for statutory activities of the Faculty of Navigation and Naval Weapons of the Polish Naval Academy.

\section{BIBLIOGRAPHY}

1. P. Blondel, A. Caiti: Buried Waste in the Seabed Acoustic Imaging and Bio-Toxicity. University of Bath, UK, 2007

2. J. Galloway, W. Collins: Dual frequency acoustic classification of seafloor habitat using the QTC view. Oceans '98, Nice, France 1998.

3. G. Grelowska, E. Kozaczka, Sounding of layered marine bottom - modeling investigations, Acta Physica Polonica A, Vol. 118, No. $1,66 \div 70,2010$

4. G. Grelowska, E. Kozaczka: Selected results of the parametric soundings of the Gdansk Bay. Hydroacoustics V. 11, 105 $\div 112$, 2008

5. G. Grelowska, E. Kozaczka, W. Szymczak: Methods of data extraction from sub-bottom profiler's signal. Hydroacoustics, 13, $109 \div 118,2010$

6. G. Grelowska: The prevailing patterns of the sound speed distribution in the environment of the southern Baltic. Archives of Acoustics, 25, 359 $\div 368,2000$

7. G. Grelowska, S. Kozaczka. W. Szymczak: Some methods of the

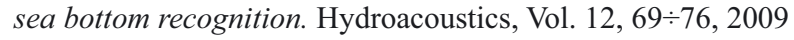

8. G. Grelowska, E. Kozaczka, S. Kozaczka, W. Szymczak: Detection of Objects Buried in the Sea Bottom with the Use of Parametric Echosounder. Archives on Acoustics, Vol. 38, No 1, $99 \div 104,2013$

9. L. Hamilton, P. Mulhearn, R. Poeckert: Comparison of RoxAnn and QTC-view acoustic bottom classification system performance for the Cairns area, Great Barier Reef, Australia. Continental Shelf Research 19, 1577 $\div 1597,1999$

10.E. Kozaczka, G. Grelowska, S. Kozaczka: Images of the seabed of the Gulf of Gdansk obtained by means of the parametric

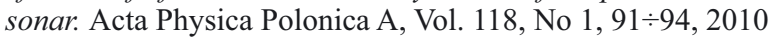

11.E. Kozaczka, G. Grelowska, S. Kozaczka, W. Szymczak: Processing data on sea bottom structure obtained by means of the parametric sounding. Polish Maritime Research, 19, 4 (76), $3 \div 10,2012$

12.K. Naugolnykh, L. Ostrovsky: Nonlinear Wave Processes in Acoustics. Cambridge University, Cambridge, 1998

13.Sternlicht D. D., Moustier Ch. P: Time-dependent seafloor acoustic backscatter (10-100) kHz. J. Acoust. Soc. Am., 114, $2709 \div 2723,2003$

14.Turgut A.: Method and apparatus of classifying marine sediment. Technical Report U. S., 1998

15.Uscinowicz S., Zachowicz J.: Geological map of the bottom of the Baltic Sea. 8 sheets and pamphlet, scale 1:200, 000, Polish Geological Institute, Warsaw, 1994

16.Walter D., Lambert D., Young D., Stephens K.: Mapping sediment acoustic impedance using remote sensing acoustic techniques in a shallow-water carbonate environment. Geo-

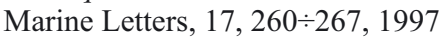

17.Wunderlich J., Müller S.: High-resolution sub-bottom profiling using parametric acoustics. International Ocean Systems, 7 (4), $6 \div 11,2003$.

\section{CONTACT WITH THE AUTHORS}

Grażyna Grelowska1), Prof., ggrel@wp.pl Eugeniusz Kozaczka1, 2), Prof., kozaczka@pg.gda.pl

Sławomir Kozaczka1), M.Sc., milites@vp.pl

Wojciech Szymczak1), M.Sc., ws2@o2.pl

1) Polish Naval Academy Śmidowicza 69

81-103 Gdynia POLAND

2) Gdansk University of Technology,

11/12 G. Narutowicza 80-233 Gdańsk, POLAND 